\title{
Time and decision making in humans
}

\author{
FLORIAN KLAPPROTH \\ Berlin Institute of Technology, Berlin, Germany
}

\begin{abstract}
Decision making requires evaluating alternatives that differ on a number of attributes. During this evaluation process, selection of options depends on the duration of the options, the duration of the expected delay for realizing the options, and the time available to reach a decision. This article reviews the relationship between time and decision making in humans with respect to this evaluation process. Moreover, the role of psychological time, as compared with physical time, is accentuated. Five topics have been selected that illustrate how time and mental representations of time affect decision making. These are (1) the duration of options, (2) temporal decision making, (3) the time between having made a decision and experiencing the consequences of that decision, (4) the temporal perspective of decision makers, and (5) the duration of the decision process. The discussion of each topic is supplemented by suggestions for further research. It is shown that psychological time is often neglected in human decision making but seems to play an important role in the making of choices.
\end{abstract}

This article was written to highlight the role that time and mental representations of time play in decision making. Making decisions usually requires evaluating at least two alternatives that differ on a number of attributes (Reed, 2004). When alternatives are evaluated, three aspects of duration matter. First, the alternatives from which a person is forced to choose the "right" one differ, among other things, regarding their duration. It is easy to imagine that the alternatives' durations might have a large impact on a decision if, for example, one has to decide between two aversive events (let's say, two dental treatments including drilling) that differ only on the duration dimension. In this case, we would expect that short events will be preferred over long events.

Second, part of the evaluation of alternatives consists of anticipating the expected time of their realization. The effect of the delay between the commitment to an option and the occurrence of a consequence has stimulated a broad range of research on so-called intertemporal decision making. Anticipating delays in realizing an option not only reduces the value of that option, but also alters its mental representation. For example, consequences occurring in the far future are represented with less detail than are consequences occurring in the near future.

Third, the time available for making choices definitely has an impact on both the amount of information that is processed and the quality of the final decision, particularly when the duration of the decision process is limited by external factors.

In order to make a beneficial decision, a decision maker has to correctly gauge the durations of the options, the durations of the expected delays in realizing the options, and the time available to reach a decision. In 2001, an article written by Ariely and Zakay was published that reviewed some issues relating time and decision making from a rather general perspective. When making suggestions for future research, they referred to the importance of perceived time, as compared with physical time, in decision making. Since publication of the Ariely and Zakay article, new data have been reported that, in fact, stress the role that psychological time plays in the making of decisions. Therefore, the present article focuses on effects on decision making that have been suggested to be dependent on the way decision makers represent time with respect to both the options and the decision process itself.

In situations in which people are forced to make decisions, particularly those realized in experimental conditions, psychological time is either imagined time or experienced time. Experienced time might lead people to choose one option over another, if both are evaluated retrospectively and are different in duration. Experienced time is affected by the amount of attention that is allocated to the processing of time, ${ }^{1}$ if people are aware that timing is relevant, or by the number of contextual changes that occur during a time period, if people do not know or suspect that they will be asked to judge duration until after the time period has ended (Block, 2003; Block \& Zakay, 1997).

Imagined time refers to either the time at which an outcome is expected to occur or the amount of time for which an outcome will last. There is evidence that imagined duration relies, at least partially, on duration experienced in the past (Roy, Christenfeld, \& McKenzie, 2005), and, therefore, quantitative modeling of imagined time should be possible (see, e.g., Eisler, Eisler, \& Montgomery, 2004, who modeled retrospective time judgments using a psychophysics approach). This means that choosing between outcomes that differ in duration or choosing between out- 
comes that differ in delay for realization might involve relying on a kind of numerical representation of that particular time. Taking this assumption for granted, one may argue that choosing one alternative over the other is at least partly dependent on how durations pertaining to the decision problem are mentally represented. In particular, one may ask whether or not decisions might be affected if the pertinent durations are in some way misrepresented.

There is ample evidence that representations of duration are biased regarding their means and their variability. Mean judgments of long durations are often shorter than their corresponding physical durations, whereas short durations tend to be judged as longer than they really are, a result that commonly is described as Vierordt's law (e.g., Predebon, 1995; Szelag, Kowalska, Rymarczyk, \& Pöppel, 2002; Wearden, 2003). Concerning the variability of temporal judgments, an estimate of duration, like estimates of most other magnitudes, will become more variable (i.e., will deviate more from its mean), the longer the duration to be estimated is (e.g., Allan, 1998; Klapproth, 2007; Wearden, 2003). This finding is a form of Weber's law.

If duration matters in decision making and if the effect of duration on decisions is due to the ability of an individual to judge time with precision, the timely aspects of decision making should be considered more thoroughly. For example, how is duration taken into account (and by which mechanisms) when duration of options is considered? Does an internal clock trigger the time of decision making under time pressure? How is time discounting related to time estimation? Does the anticipation of delays in intertemporal choices depend on the individual's time perspective?

To address these questions, I attempted in this review to accentuate the relationship between decision making and both aspects of time - the physical as well as the psychological aspect. Recent studies have revealed that internal timing mechanisms might support people in making fast decisions (Macar \& Vidal, 2003, 2004; MacDonald \& Meck, 2004; Praamstra, Kourtis, Kwok, \& Oostenveld, 2006), that brain activity during delay discounting has some resemblance to neural activation during time estimation (Wittmann, Leland, \& Paulus, 2007), and that the representation of time itself may influence intertemporal choices (Berns, Laibson, \& Loewenstein, 2007; Takahashi, Oono, \& Radford, 2008).

Time matters within the decision-making process at least regarding the evaluation of alternatives and with respect to the process itself. Concerning these aspects of decision making, I have subdivided this article into five sections. Selection of these sections was further motivated by the fact that recent findings regarding relationships between psychological time and decision making have been made primarily with respect to these topics.

The first section will deal with the durations of the alternatives about which a person has to decide and how the alternatives' durations influence the choice in favor of one alternative. The second section will consider a special case of the first section. It will illustrate choices for which duration is the only relevant attribute of the options, a form of decision making that is documented in the literature as temporal decision making. The third section will be about choosing between delayed outcomes, usually called intertemporal choices. It comprises four subsections that will present (1) the description of a classical model of temporal discounting, (2) differences between exponential and hyperbolic delay discounting, (3) the relationship between delay discounting and time perception, and (4) the connection between delay discounting and the mental representation of the future. In intertemporal choices, decision makers have to anticipate delays that separate the decision from its consequences. The fourth section will relate decision making to the traits of an individual that account for his or her future time perspective - that is, how he or she anticipates personal future goals and actions. As compared with the paradigm for intertemporal choices, this section will provide alternative views on how future outcomes are valued. The fifth and last section will consider the duration of the decision process, which has often been reported to influence the decision outcome. This section will be subdivided into two parts, one referring to decision making under limited time resources, the other presenting literature with respect to choice reaction time tasks. Making decisions under time pressure might require that decision makers engage in estimating the time available for the decision.

At the end of each section, the main findings will be summarized, conclusions will be offered, and questions or suggestions for future research will be presented.

\section{RELATIONSHIPS BETWEEN TIME AND DECISION MAKING IN HUMANS}

\section{Duration of Options}

This section reviews literature bearing on the impact that the durations of alternatives has on choosing between those alternatives.

\section{Review of the Literature}

On the basis of the fact that decision makers usually resort to nontemporal features of an experience (such as slope, end, and peak) when evaluating it, Kahneman and co-authors (e.g., Kahneman, Fredrickson, Schreiber, \& Redelmeier, 1993; Redelmeier \& Kahneman, 1996) suggested that people ignore or severely underweight the duration of consequences, which they called duration neglect. They found in several studies that evaluation of experiences was based primarily on the intensities of the experiences, rather than on the durations of the experiences. For example, Varey and Kahneman (1992) presented subjects with hypothetical experiences that differed in duration and in intensity over time and asked them to provide a global evaluation of each experience on a 0-100 scale. They found that ratings of these experiences were based on the maximum and final intensities of the experiences, with little weight on duration. Fredrickson and Kahneman (1993) focused on the role of duration in overall retrospective ratings of affective episodes. In one experiment, the authors showed subjects long and short movie clips that were either pleasant or unpleasant and asked them to provide a global rating of the pleasantness of the experience. 
They found that duration had little impact on these overall evaluations. Redelmeier and Kahneman (1996) conducted a study with patients who underwent colonoscopy or lithotripsy. The patients were then asked to report the total pain they had experienced, on a 10-point scale. The treatments in their study varied in the amount of time they took. Nevertheless, the results showed no significant correlation between the duration of the procedure and its retrospective evaluation. Hands and Avons (2001) conducted a series of experiments in which participants were asked to evaluate television sequences that were affected by transient picture impairments. Rating of the quality of the television sequences was dependent mainly on the peak impairment intensity, but the duration of an impairment was found to have little impact on quality ratings.

However, other studies have obtained less support for duration neglect, at least with aversive stimuli. For instance, Schreiber and Kahneman (2000) found that longer unpleasant sounds were evaluated as worse than shorter sounds. Another factor that seems to attenuate duration neglect is the focus of the subjects' attention. Rinot and Zakay (1999) let some subjects evaluate the overall annoyance they experienced from each sound in a series of annoying sounds and let others evaluate both the overall annoyance and the duration of each experience. The overall evaluations in the latter condition were more sensitive to duration than were those in the former condition. Read and Loewenstein (1999) investigated their subjects' willingness to experience different durations of pain in exchange for payment. They revealed that willingness to accept (WTA) pain depended strongly on the duration of the pain and that this relationship was clearly nonlinearthat is, the increase of WTA was larger at short durations than at long durations.

There is mixed evidence that duration plays a role when people select among alternative courses of action in order to save time. Time-saving decisions are characterized mainly by the attempt to choose options that have the shortest duration-for example, when deciding whether to drive to the university by car (which will take about $30 \mathrm{~min}$ ) or to take the bus (which will last 15 min longer). However, the decision for a certain amount of time loss is confounded with the probability with which the time loss is expected to occur. In a series of studies, Leclerc, Schmitt, and Dubé (1995) presented their subjects with various scenarios that involved a selection between two alternatives carrying an identical expected loss of time. In each scenario, subjects were required to choose between a certain time loss and a variable time loss (e.g., having to wait $60 \mathrm{~min}$ for sure, or a $50 \%$ chance of waiting $30 \mathrm{~min}$ and a $50 \%$ chance of waiting $90 \mathrm{~min}$ ). In most cases, the subjects selected the certain loss rather than the variable loss, hence ignoring the durations of the options. Krishnamurthy and Kumar (2002) could furthermore show that risk aversion to waiting time was stronger when people imagined themselves as being confronted with a scenario than when they imagined other people making the choice.

Indeed, evaluation of waiting time has been shown to be better when people are informed about the expected length of the wait than when no information is provided regarding the wait duration, independently of the actual duration of the wait (Dellaert \& Kahn, 1999; Hui \& Tse, 1996; Hui \& Zhou, 1996). Thus, a wait appears to be less aversive the more predictable its duration is.

A different pattern of results, however, has been found when decisions are made from experience. Whereas scenario-based studies of time-saving decisions tend to reflect risk aversion (Krishnamurthy \& Kumar, 2002; Leclerc et al., 1995), Munichor, Erev, and Lotem (2006) found that time-saving decisions reflected a tendency to prefer options that led to the best outcomes (i.e., the shortest durations) when decision makers had to rely on personal experiences.

Ariely and Loewenstein (2000) examined the impact of different evaluation methods on the role of duration in evaluations. They used a range of procedures, such as ratings, willingness to pay, and a graded-choice procedure in which subjects repeatedly chose between annoying sounds. Comparing these evaluation methods, they found that the rating procedures commonly used in previous research elicited the least sensitivity to duration. However, decisions or comparative ratings corresponded with an increased weight that people placed on duration.

\section{Summary, Conclusion, and Suggestions for Future Research}

The majority of experiments being reviewed have shown that the durations of options played only a negligible role in decision making. However, there are some cases in which duration seems to be considered for judgment: (1) when choices have to be made between aversive stimuli; (2) when decision makers pay attention to the durations of the options; (3) when durations are certain, rather than uncertain; (4) when durations are experienced, rather than imagined as part of a scenario; and (5) when people choose between options, rather then evaluating them.

Ariely and Loewenstein (2000) picked up the latter point and argued that the role of duration should be considered separately in two aspects of behavior: encoding and making choices. They suggested that when the goodness and badness of experiences are encoded, ignoring duration is not necessarily a mistake and can even be desirable. The idea here is that, in many cases, overall evaluations are used to classify events into classes of desirable and nondesirable objects, and their duration is often a separate factor that can be considered later (at the choice stage). In the case of making choices, however, the role of duration should be very different. When choosing, it would be a mistake not to take duration into account, since this could cause a wrong allocation of time to different activities.

Why duration sometimes matters and sometimes does not has not been clarified yet. Presumably, encoding of duration is impaired when duration is of minor importance for the decision maker or when attention is distracted from duration. It is well known from timing experiments that timing becomes less accurate when attention is devoted mainly to nontemporal information processing (e.g., Brown, 1997).

A possible attempt to examine more directly whether and how duration matters in choice is to systematically vary 


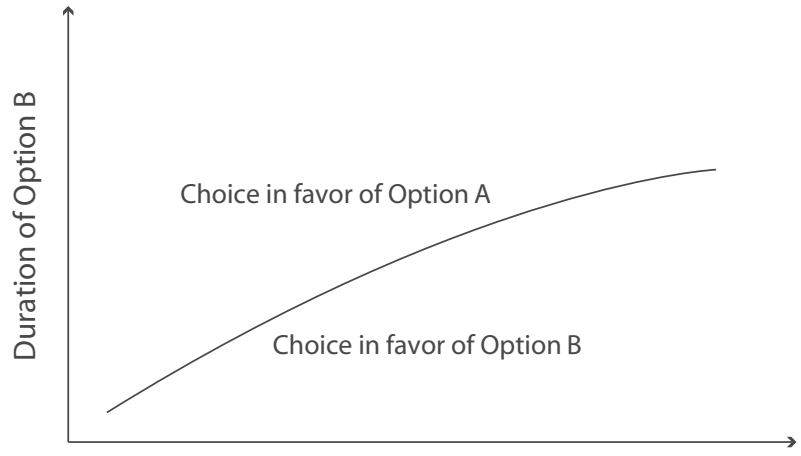

Duration of Option A

Figure 1. Possible relationship between the duration of Option $A$ and the duration of Option B. The area above the solid line represents the choices in favor of Option $A$; the area under the line, the choices in favor of Option B.

stimulus duration while keeping any other stimulus attribute constant. Suppose that there are two options: Option A is a very unpleasant event, and Option B is a less unpleasant (yet not pleasant) event. Holding the duration of Option A constant while varying the duration values of Option B would yield a particular duration of $\mathrm{B}$ at which the preference for Option A equals the preference for Option B. For example, a 10 -sec surge with high intensity might correspond to a 60 -sec surge with low intensity. In this example, the high-intensity surge equals in preference a low-intensity surge with a duration six times higher than that of the highintensity surge. However, selecting durations for Option A other than the one used in this example would yield other values of duration that belong to Option B.

Figure 1 illustrates the subjective equivalence between both option durations. Assuming that there would be a linear relationship, Option A would be chosen with the same frequency as Option B multiplied by a constant factor. ${ }^{2}$ However, nonlinear relationships are also conceivable (as is indicated in the figure). Deviations from linearity would imply that the duration of options is not a constant weighting factor of intensity when preferences are made.

\section{Temporal Decision Making}

Temporal decision making is treated here as a special case of choices made between alternatives differing in duration.

\section{Review of the Literature}

When people choose between options of different duration, the best alternative is usually one that is evaluated as being most pleasant or as having the highest utility. However, decisions are conceivable where people do not care about the pleasantness or the utility of experiences but focus on duration as the only relevant attribute of an experience. For example, an individual must decide when to switch off the oven in order to prevent the cookies from baking too long and getting burnt. Essentially, and provided that no external clock aids the process of time keeping, he or she must estimate the passage of time to come to an appropriate decision.
What makes a decision a temporal decision? To answer this question, I will present a very simple example of a time estimation task that is frequently used in time research laboratories, called temporal generalization (see, e.g., Klapproth, 2002; Wearden, 1992; Wearden, Denovan, Fakhri, \& Haworth, 1997). In this task, a person is initially exposed to a standard duration (e.g., a tone of $400 \mathrm{msec}$ duration). After a few exposures to the standard, comparison durations are presented that are longer than, shorter than, or equal to the standard duration. The subject has to judge whether each of the comparisons is the standard or not, simply by giving a yes or a no response (usually via a keypress). In most of the studies reported in the literature, feedback as to performance accuracy is given to the subjects.

What does the subject have to do when judging the duration of the stimulus? First, he or she has to encode the duration of the standard being presented at the beginning. This might be done by an internal device that operates in a way similar to an oscillating neuron that emits pulses with regular frequency. Then the standard duration must be stored into memory for the purpose of later comparisons. The comparison durations presented as test stimuli likewise need to be encoded, and, finally, both the internal representation of the standard and the internal representation of the comparison have to be checked regarding their equality. Even if the comparison and standard durations were physically the same, it seems unlikely (due to noise in information processing) that they will be exactly subjectively equal. Therefore, the subject needs a criterion that allows him or her to decide whether the two durations are subjectively close enough to elicit a yes response.

Even this simple task involves at least three mental operations: the encoding of stimulus duration, memorization of stimulus duration, and a decision process that is needed to generate the similarity decision.

Gibbon, Church, and Meck (1984), who conducted temporal generalization experiments with rats, proposed an information-processing model of temporal discrimination, the scalar timing theory. The scalar timing theory was initially developed to explain regularities in the timing behavior of rats and pigeons (Church \& DeLuty, 1977; Church \& Gibbon, 1982) and was then extended to human timing performance (Wearden \& McShane, 1988). The key assumptions of this theory are (1) that estimates of real duration are, on average, accurate and (2) that standard deviations of time estimations grow proportionally with the mean of time estimations. The latter relationship is a form of Weber's law. Scalar timing theory assumes three levels for the processing of temporal information (see Figure 2). The highest level is the clock level, consisting of a pacemaker-accumulator device. The pacemaker generates pulses that are recorded and added by an accumulator. The content of the accumulator is then transferred into memory (the next level). Finally, there is a decision level, at which the comparison is made between a sample of the standard drawn from memory and the duration of a comparison stimulus represented in the accumulator. (Note that some authors distinguish between working memory and the accumulator. For the sake of simplicity, both instances are treated here as being identical.) 


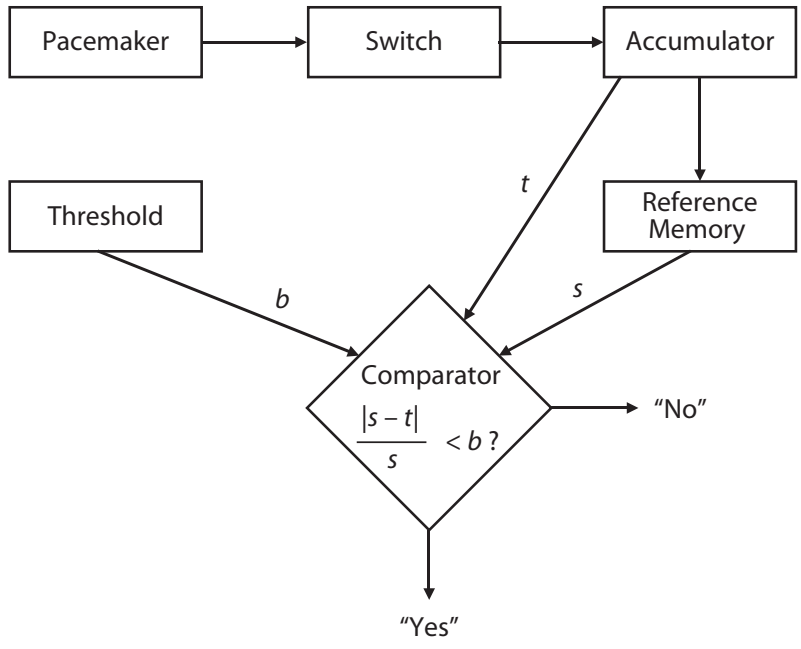

Figure 2. An information-processing model of scalar timing. The clock consists of a pacemaker, a switch, and an accumulator. The value in the accumulator $(t)$ is compared with a sample of a value in the reference memory $(s)$ according to a ratio rule on the basis of a sampled threshold value $(b)$. The output of the comparison is a decision indicating either perceived sameness ("yes") or difference ("no") of two presented intervals. From "Application of Scalar Timing Theory to Individual Trials," by R. M. Church, W. H. Meck, and J. Gibbon, 1994, Journal of Experimental Psychology: Animal Behavior Processes, 20, p. 136. Copyright 1994 by the American Psychological Association. Adapted with permission.

Decision processes seem to be an essential part of the timing system, and different decision processes have been proposed for different sorts of timing tasks, but most variants of timing tasks seem to encourage a form of decision making that is called the thresholded normalized difference model (Wearden, 2004). This means that judgments of the similarity or identity of durations appear to be done by calculating the absolute difference between a to-be-judged duration (comparison) and some kind of standard duration and then normalizing this difference by some quantity (e.g., the standard or the comparison duration). This result is then compared with a certain threshold value.

Modeling temporal generalization easily illustrates how hypothetical decision processes with respect to stimulus duration might work in humans. A temporal generalization task begins with a number of presentations of the standard, $s$, which is assumed to reside in memory. The memory is assumed to be represented as a Gaussian distribution with an accurate mean and some coefficient of variation (standard deviation/mean). On each trial, a random sample, $s^{*}$, is drawn from memory of $s$, and the subject identifies a comparison duration, $t$, as the standard if $\operatorname{abs}\left(s^{*}-t\right) / t<b^{*}$, where $s^{*}$ is a sample from the standard represented in memory, $t$ is the representation of the comparison duration, and $b^{*}$ is a threshold variable from trial to trial with a constant mean. ${ }^{3}$

Among the various manipulations that have led to changes in timing performances of humans, only a small number of factors that might affect decision processes alone have been reported. These are (1) task difficulty, (2) the payoff structure, and (3) time pressure.
Ferrara, Lejeune, and Wearden (1997) let two groups conduct a temporal generalization task and varied the spacing of comparison durations between them. One group received comparison durations spaced in 150-msec steps (the easy group), whereas the other group had comparison durations spaced in 75-msec steps (the difficult group). Ferrara et al. found that discrimination between the comparisons and the standard was better in the group with the 75 -msec spacing. This result was replicated by Wearden and Grindrod (2003), who again found apparently greater timing sensitivity when discrimination was more difficult. Ferrara et al., as well as Wearden and Grindrod, offered a possible explanation by assuming a lower value of the threshold $b$ (i.e., a stricter threshold) in the difficult condition, as compared with the easy condition.

In the same study, Wearden and Grindrod (2003) manipulated the temporal decision process by encouraging or discouraging people to make yes responses in a temporal generalization task by awarding or deducting points. Encouraging identifications of the standard increased the proportion of identifications of the standard, whereas the discouraging manipulation decreased identifications of the standard. Modeling showed that the main theoretical difference between the two conditions was due to a change in the decision threshold.

In a recent article, Klapproth and Müller (2008) used response times to detect not only which temporal decisions were made, but also when they were made. They required subjects within a temporal generalization task to make time judgments either normally, taking as much time as they wanted, or as quickly as possible, regardless of whether all the stimuli judged had actually been terminated. Performance was different in the two conditions, and strong evidence was found from reaction time measures that people could make timing decisions before the stimuli had finished. This result indicated how much temporal information was needed to make temporal decisions.

\section{Summary, Conclusion, and Suggestions for Future Research}

Decision processes play an essential role in timing, as is suggested by one of the most prominent theories of temporal processing, the scalar timing theory, and its modifications. Decision processes in timing can be modeled by assuming that perceived differences of durations are normalized and then compared with a decision threshold. Decision processes are subject to manipulation by varying (1) task difficulty, (2) the payoff structure of the task, and (3) the time available for the decision. Whereas manipulating task difficulty will lead to changes in the variance of time estimations, variations of both the payoff structure and time pressure will change the mean of temporal judgments.

To conclude, the effects of manipulating the decision process in temporal decision making are compatible with assumptions derived from scalar timing theory.

Much work has been done to model decision processes in timing tasks, such as temporal generalization and temporal bisection. However, tasks remain that are still little understood in terms of the mental processes underlying 
these tasks: for example, the production and reproduction of temporal intervals, as well as verbal estimations of experienced periods of duration. Future research should investigate to what extent existing models of temporal decision making can explain timing behavior elicited by the latter tasks. Some first steps have been taken: Wearden (2003), for instance, applied principles of scalar timing theory to the method of temporal reproduction; in another article (Wearden, 2004), the process of verbal estimation was analyzed in some detail.

Moreover, the time course of temporal decision making should be looked at more thoroughly, since it might give more insight into what is actually processed in temporal processing. Analyzing real-time processes in temporal decision making by using quantitative decision models has been discussed by Klapproth (2003b) and Klapproth and Müller (2008).

\section{Time Between Decisions and Consequences}

Anticipating delays that separate a decision from its consequences has been reported to have a large impact on the outcome of a decision. The next section will review the literature pertaining to this issue.

\section{Review of the Literature}

The discounted utility model. The time span between the instant when a decision is made and the realization of its outcomes is an important factor that alters the decisionmaking process substantially. An immediate reward is, on average, more attractive than the same reward paid out after some weeks have elapsed. This phenomenon, known as temporal discounting, was first described by the discounted utility (DU) model (Samuelson, 1937), according to which the utility of a consequence exponentially decreases as the delay for the consequence increases.

Experimental research on temporal discounting involves both real consequences and delays, as well as hypothetical choice scenarios. Since the latter allow the study of a much broader range of delays, they have usually been preferred by researchers. In many studies, the consequences under consideration are amounts of money. Data typically are collected individually, with the goal of depicting each individual's tendency to discount delayed outcomes by means of an empirical discounting function. On each trial, subjects choose between a small reward that is available immediately (or in the near future; see, e.g., Green, Myerson, \& Macaux, 2005) and a large reward that is available in the far future. Across many trials, the delay for the large reward and the amount of the small reward are varied. The goal is to identify the current subjective value of outcomes of various delays, with subjective value defined as the magnitude of the small reward that generates indifference in a choice against the large reward. This subjective value suggests the extent to which a large reward has been discounted because of delay. An example might illustrate the experimental procedure typically applied. In one experimental condition, the amount and delay of the large reward may remain constant (e.g., $€ 1,000$ to be given in 1 year), whereas the amount of the small reward varies across trials from near zero to equal to that of the large reward. If the small reward values are presented in ascending order, initially, the large reward is likely to be preferred (e.g., $€ 1,000$ in 1 year instead of $€ 1$ now). As the small reward grows larger (e.g., $€ 1,000$ in 1 year as opposed to $€ 990$ now), preference shifts to the small reward. The value of the small reward at which the preference switches defines the current subjective value of the large reward or, in other words, the amount of discounting of the large reward due to delay. A discounting function can be derived for any individual subject when subjective values have been estimated for the same large reward at several delays. This discounting function shows the extent to which subjective value changes under delay. Usually, discounting functions are decelerating - that is, the more temporally distant an expected consequence, the weaker its impact on current behavior.

A central assumption of the DU model is that intertemporal choice can be expressed by a single parameter, the discount rate (Frederick, Loewenstein, \& O'Donoghue, 2002). In its original form, the DU model assumed a constant discount rate. The intertemporal utility function in the DU model can be described by the following equation:

$$
U_{t}\left(c_{t}, \ldots, c_{T}\right)=\sum_{k=0}^{T-t} D(k) u\left(c_{t}+k\right),
$$

with $D(k)=[1 /(1+\rho)]^{k}$.

In this equation, $u\left(c_{t}+k\right)$ is the utility function (expressing the utility of a reward $c$ at the instance $t+k), T$ is the time horizon, and $D(k)$ is the individual discount function (expressing the relative weight of a reward at $t+k$, as compared with its weight at $t) ; \rho$ represents the discount rate - that is, the amount by which a future reward is discounted, as compared with an immediate reward.

Exponential versus hyperbolic discounting. Constant discount rates imply exponential discounting. However, the most commonly described discounting behavior is hyperbolic, which means that delayed rewards are discounted by functions that are inversely proportional to delay (e.g., Glimcher, Kable, \& Louie, 2007; Green \& Myerson, 1996; Jones \& Rachlin, 2006; Myerson \& Green, 1995; Rohde, 2005). Hyperbolic discount functions decay at a more rapid rate for short time periods than for long time periods, which means that a hyperbolic discounter is more impatient when short-run trade-offs are made than when trade-offs for the long run are made (Berns et al., 2007). Hyperbolic discounting is also consistent with the finding that humans can change their preferences between two delayed rewards in favor of the more proximate reward as the time to both rewards decreases (Green, Fristoe, \& Myerson, 1994; Kirby \& Herrnstein, 1995).

Although human delay discounting, for the most part, is best explained by a hyperbolic discounting function, there is some evidence that humans can be less impulsive than is predicted by hyperbolic discounting and can behave in a more rational manner. Forzano and Logue (1992) showed that subjects are more impulsive in conditions when, after each choice, juice is given during the experiment, as compared with conditions in which subjects are provided with 
money or points exchangeable for juice at the end of the experiment. Loewenstein (1996) found that visceral factors, such as hunger, thirst, and sexual desire, might increase impulsivity but that controlling for these factors will result in less impulsive behavior. Montague and Berns (2002) proposed that uncertainty in decision situations will encourage a steeper (i.e., hyperbolic) discounting than will occur when there is no uncertainty, the latter condition leading, rather, to exponential discounting. Recently, Schweighofer et al. (2006) let subjects conduct a delay-discounting task in which the time to gain maximal reward was limited and delays were experienced rather than imagined. They found that their subjects adopted exponential discounting, which, in effect, maximized reward at the end of the experiment.

Delay discounting and time perception. Recently, Takahashi et al. (2008) suggested that human intertemporal choice is strongly influenced by the psychophysics of time perception. They proposed that time perception follows the Weber-Fechner law (i.e., assuming a logarithmic relationship between subjective and objective time) and tried to combine the psychophysics of time perception with the classical DU model (exponential discounting). This was done by replacing the physical duration of delay in the DU model by the subjective delay, expressed as $\tau=a \ln (1+b D)$, where $\tau$ is the subjective delay, $D$ is the physical delay, and $a$ and $b$ are free parameters. Takahashi and co-workers could show that the behavioral data yielded by a delay-discounting task were fit best by the Weber-Fechner discounting function, as compared with hyperbolic discounting and exponential discounting.

The assumption that temporal discounting is related to time perception has also been confirmed by studies with subjects who showed both impulsivity in delay discounting and impairments in time estimations. For example, drug addicts are supposed to be more impulsive than nonaddicts (Fillmore \& Rush, 2002; Leland \& Paulus, 2005). They show less self-control in decision-making tasks, since they discount future rewards more strongly than do control subjects; that is, they tend to prefer smaller and sooner over larger but later rewards (Hoffman et al., 2006; Kirby \& Petry, 2004). Stimulus-dependent subjects also show impairments in time perception and sensorimotor timing (e.g., Sayette, Loewenstein, Kirchner, \& Travis, 2005). In a study conducted recently by Wittmann, Leland, Churan, and Paulus (2007), drug addicts and nonaddicts were compared regarding their ability to estimate time and to tap in synchrony with a regular tone sequence. They found that drug addicts needed larger time differences for effective duration discrimination than did control subjects, particularly for intervals around $1 \mathrm{sec}$. Moreover, drug addicts accelerated finger tapping when the tone sequence was removed and they still had to tap with the same rhythm. In addition, drug addicts overestimated long intervals. The authors concluded that the differences in time processing could be attributed to the larger impulsivity of addicts, as compared with nonaddicts, and that these differences might explain why addicts have difficulty in delaying gratification.

Similar results were obtained with patients who suffered from damage to the orbitofrontal cortex (OFC). These patients have generally been supposed to be more impulsive than controls, and it could be shown that OFC patients also overestimated time intervals verbally and underestimate time intervals by the method of time production (Berlin, Rolls, \& Kischka, 2004).

Impulsivity and strong temporal discounting of delayed rewards have also been observed in adolescents with attention deficit hyperactivity disorder (ADHD). As compared with control subjects, ADHD patients discounted delayed monetary rewards more strongly and made larger errors of reproduction (i.e., absolute difference from the objective duration; Barkley, Edwards, Laneri, Fletcher, \& Metevia, 2001).

Wittmann, Leland, and Paulus (2007) found different levels of brain activity during a delay-discounting task when choices varied between immediate and delayed rewards and when the delays varied between less than a year and 1 year or longer. They concluded that decisions of whether to opt for a sooner or later reward require cognitive processing of time and that this processing corresponds to neural activation (e.g., in the striatum) that also plays a role in time estimation.

Delay discounting and the representation of the future. The core assumption of temporal discounting is that the value of an outcome is discounted as temporal distance from the outcomes increases. However, Trope and Liberman (2003) showed that the effect of temporal distance on the attractiveness of an option depends on the value associated with the option. For decisions in the near future, practical aspects should be more heavily weighted, and for decisions far in the future, desirability aspects should be more important. In their construal level theory, Liberman and Trope (1998) proposed that temporal distance systematically changes people's mental representations of future events and that these changes determine the value of those events (Trope \& Liberman, 2003). They distinguished between high-level construals and low-level construals. High-level construals involve the abstract representation of events, basically comprising global features, whereas low-level construals include rather peripheral, concrete, and local features. Construal level theory suggests that the representation of distant future events will be more abstract, broad, and structured (high level) than the representation of near future events (low level).

Temporal distance should increase the weight of highlevel value and decrease the weight of low-level value. As a result, temporal distance should shift the overall attractiveness of an option closer to its high-level value than to its low-level value. Therefore, when the low-level value of an option is more positive than its high-level value, the option should be more attractive in the near future, which is also proposed by time-discounting theories. However, when the high-level value of an option is more positive, the option should be more attractive in the distant future. For example, temporal distance should increase the preference for gambles with a low probability of winning a large prize but decrease the preference for gambles with a high probability of winning a small prize (Sagristano, Trope, \& Liberman, 2002).

Moreover, many decisions are seen in a different light as the time approaches to put them into practice, since people 
place greater weight on concrete and practical considerations, relative to more vague and abstract dimensions, for desirability. For instance, people may revise a decision already made when the moment to implement it arrives (for an overview, see Loewenstein, Weber, Hsee, \& Welch, 2001). In a study of Welch (1999), for example, students were offered a payment of $\$ 1$ in exchange for telling a joke in front of a class the following week. When the appointment came closer, both the students who had agreed to tell the joke and those who had declined to do so were given the opportunity to change their minds. It was shown that $67 \%$ of those who initially volunteered decided not to tell the joke, whereas none of those who had initially declined the offer changed their minds and decided to tell the joke at the last minute.

There is evidence showing that events occurring at relatively closer temporal proximities are processed differently than events occurring in more distant proximities (Sanna \& Chang, 2006). When events are presented as occurring at more distant temporal proximities, individuals are more susceptible to fallacies (Sanna, Parks, Chang, \& Carter, 2005), valenced information (Liberman, Sagristano, \& Trope, 2002), and optimistic bias (Gilovich, Kerr, \& Medvec, 1993), relative to when events are occurring at close temporal proximity. McElroy and Mascari (2007) investigated how temporal proximity of options influences decision task processing and, in turn, the likelihood of framing effects. ${ }^{4}$ They proposed that events occurring at more distal temporal points will be perceived as less relevant than events occurring at more proximal points. Hence, events occurring in close temporal proximity should also be processed using a more effortful, analytic processing style. Under these conditions, decision makers should rely on the numeric magnitude of the alternatives, rather than on the presentational frame. However, if the individuals perceive the event as occurring in relatively distant temporal proximity, they should perceive the event as less relevant and should be more likely to use the less effortful, holistic processing style, resulting in more robust framing effects. McElroy and Mascari confirmed their hypotheses by manipulating both the temporal proximity of alternative options and the framing of options as either gains or losses. Framing effects were more attenuated if the event was expected to occur in relatively close proximity than if it was expected to occur at a distant point of time.

Read, Frederick, Orsel, and Rahman (2005) found that discount rates were markedly lower when delays were described as calendar dates (e.g., on October 17) than when they are described in terms of time intervals (e.g., in 6 months). This date/delay effect might be attributed to the way time is represented in either condition. Read et al. presented some explanations for the results they obtained, which refer to the mental representation of time. For example, they assumed that the date framing might have caused the temporal interval to be underestimated, since the subjects presumably did not realize the "real" temporal distance between two successive dates. Although there are certainly other accounts that might explain the results as well without particularly considering time representation, it has become clear that thinking about the future strikingly depends on the description of temporal intervals. Thus, the framing within which temporal intervals are described might lead to different representations of time and, hence, to different temporal judgments.

Indeed, there is good reason to assume that there are multiple ways of representing time. Friedman (1990), for example, distinguishes between (1) spatial images of temporal intervals (e.g., the distance between June and September represented as the spatial distance between two numerals lying on a ruler), (2) verbal coding of temporal order (e.g., representing the order of months as a chain of names), and (3) the meaning of time (e.g., July might be associated with hot and beach).

\section{Summary, Conclusion, and \\ Suggestions for Future Research}

Preferring outcomes that occur now, as compared with outcomes that will occur in the future, has been explained by models that assume that the value of future events is discounted. Quantitative models exist that relate the discounted outcome to the delay of its realization. Psychological motives that could account for delay discounting are, among others, visceral influences, uncertainty about future outcomes, and impulsivity. However, the myopia for the future may also be a product of the way the future is mentally represented. Representing future events more abstractly than temporally nearer events might lower the value of future events. Thinking in dates, rather than in intervals, might lead to underestimations of the delays. Reduced abilities to correctly estimate time intervals might cause people to discount the future more than they do when they succeed in time estimation.

Apparently, there is a lack of a global account that incorporates the different effects of subjective time on discounting the future. Presumably, this might be the case because subjective time is a heterogeneous construct, ranging from the quantitative representation of intervals between milliseconds and minutes to the qualitative and meaningful concept of time (see, e.g., Klapproth, 2003a; Pöppel, 1998).

Thus, it seems necessary to examine more closely how subjective time affects temporal discounting. One promising possibility might lie in investigating the connection between time estimates and discount rates experimentally. Another approach involves the assessment of the time perspective of individuals and relating this time perspective to the selection of options in classical decision tasks. The next section will deal with this issue.

\section{Decision Making and the Future Temporal Perspective}

As compared with the paradigm for intertemporal choices, this section will provide alternative views on how future outcomes are regarded.

\section{Review of the Literature}

Delay discounting means that rewards that will be delivered in the far future will be devalued more than rewards that will be delivered in the near future. This effect, commonly obtained when using a delay-discounting task, might be traced back to at least two possible reasons. First, 
the delay might be perceived by decision makers as a barrier leading to psychological or monetary costs (see, e.g., Leclerc et al., 1995; Osuna, 1985) that will exceed the benefits of the potential outcomes. Second, decision makers who strongly devalue future outcomes might be more myopic regarding the future than are decision makers who do not or just mildly devalue future outcomes. According to this argument, people who are not able to regard the far future will also disregard consequences that might occur in the far future. Therefore, due to their myopia with respect to events that might happen in the distant future, they prefer to choose consequences that will appear immediately or at least in the proximal future (e.g., Hodgins \& Engel, 2002; Lilienfeld, Hess, \& Rowland, 1996). This second argument suggests that people who have a strong propensity for delay discounting might also suffer from a short temporal perspective on the future.

Future temporal perspective is commonly defined as the present anticipation of future goals (Simons, Vansteenkiste, Lens, \& Lacante, 2004). People with a rather short future temporal perspective set most of their goals in the near future, whereas people with a rather long or deep temporal perspective are striving toward goals that are situated in the more distant future. It has been found with several investigations that the anticipated value of a future goal decreases the more the future goal is delayed in time (e.g., Ainslie, 1992; Rachlin, 1995). Since psychological distance toward goals in the distant future is shorter for people with a long future temporal perspective than for those with a short future temporal perspective, the decrease in anticipated value as a function of temporal delay is less steep for them (Simons et al., 2004).

There have been several attempts, reported in the literature, to assess the time perspective of individuals. Some researchers conceive time perspective as a personal trait (e.g., Strathman, Gleicher, Boninger, \& Edwards, 1994; Zaleski, 1996). These authors developed questionnaires whose aim was to measure the extent to which an individual's behavior is guided by future events. A comprehensive measure that captures all three dimensions of temporal perspective (past, present, and future) is the Zimbardo Time Perspective Inventory (Zimbardo \& Boyd, 1999). This questionnaire comprises five factors (past-positive, past-negative, present-hedonistic, present-fatalistic, and future orientation), of which only the present and the future perspective factors serve as predictors of immediate, pleasure-oriented goals versus long-term goals (Henson, Carey, Carey, \& Maisto, 2006). Others have sought primarily to assess the extension of the time horizon. Extension has been examined, for example, by the length of time (in years) between the participant's actual age and the age at which the most distant event would occur (e.g., Greene, 1986; Lessing, 1972; Wallace, 1956).

Wilson and Herrnstein (1985) already associated the behavioral measure of time discounting with the construct of temporal perspective (here, the time horizon). They assumed that individuals who discount time at rapid rates also have a short future time horizon. Shortened time horizons have been demonstrated in persons with substance addictions as well and are hypothesized to provide an ex- planation for the persistence of substance use by addicted persons despite the clear risk of negative consequences (Petry, Bickel, \& Arnett, 1998; Smart, 1968; Wills, Sandy, \& Yaeger, 2001). For example, Petry et al. (1998) examined time orientation in heroin addicts and demonstrated that addicts were less future oriented than matched control subjects without addiction problems. Heroin addicts were also likely to choose small, immediate rewards over large, delayed ones in a card game. Similar findings were reported with social drinkers (Smart, 1968). Hodgins and Engel (2002) examined whether pathological gambling was associated with shortened time horizons by administering the Zimbardo Time Perspective Inventory and the Future Time Perspective Inventory (Wallace, 1956) to a group of pathological gamblers, a group of psychiatric day patients, and a group of social gamblers. They found significantly shorter time horizons in pathological versus social gamblers but only small differences between pathological gamblers and psychiatric patients, which indicated that shortened time horizons were not restricted to addicted people.

Time perspective seems to correlate with many aspects of everyday behavior. In general, people with a high degree of future orientation exhibit more thoughtful behavior, whereas people with a rather low degree of future orientation tend to engage in more risky and unhealthy behaviors (Zimbardo, Keough, \& Boyd, 1997). People who give more consideration to the consequences of future events reported fewer behaviors that would have negative long-term effects on their health, such as drinking alcohol and smoking, than did those who were less aware of the future (Keough, Zimbardo, \& Boyd, 1999).

Despite all the results mentioned above, until now, little research has been done on the question of whether there is a direct relationship between the discounting of future rewards and the way individuals mentally represent their own future. It might be hypothesized that people having a strong propensity for delay discounting should also have a less extended time horizon or should score lower on a future time perspective scale than will people with a rather weak propensity for delay discounting. To examine this question, Fellows and Farah (2005) investigated the effects of dorsolateral frontal (DLF) and ventromedial frontal (VMF) lobe damage on two aspects of temporal foresight - namely, temporal discounting and the future time perspective (measured by an adaptation of Wallace's [1956] list of future life events). The subjects were patients with DLF damage who were reported to be myopic for the future (e.g., Bechara, Dolan, \& Hindes, 2002), patients with VMF damage, patients with brain lesions outside the frontal lobes, and normal individuals. Delay discounting did not substantially differ among the four groups. Moreover, subjects also did not differ regarding the number of future events generated within the Wallace task. However, the extension of future time perspective (i.e., the maximum temporal distance of a future event generated by each subject) was highest for the controls and lowest for the VMF patients, with DLF patients and patients with lesions outside the frontal lobes lying in between. The surprising fact that VMF damage did not in- 
fluence temporal discounting rates but did affect personal future time perspective let the authors speculate that the discounting task was presumably less sensitive than the future time perspective task.

\section{Summary, Conclusion, and Suggestions for Future Research}

Some researchers have argued that people can be differentiated regarding their proneness and their ability to look into the future. Different approaches exist to examine this ability, ranging from questionnaires to listing personal future events. Short time horizons and little future orientation have been shown to correspond to preferring immediate rewards over remote rewards. However, studies in this area are rare, and further research is strongly needed.

In conclusion, it can be said that whether future temporal perspective is a trait or is subject to manipulation is still an open question. Moreover, it is a matter of debate how a present-oriented time perspective relates to impulsiveness obtained with delay discounting tasks.

Therefore, examining the diverse interrelationships between decision making and the future time perspective might involve correlational analyses of measures of delay discounting - for example, the discount rate - and the temporal perspective obtained from different measures and in various contexts. Since temporal perspective also depends on the specification of the anticipated aspects of the future (Stern \& Koerber, 2000), I furthermore suggest assessing the subjects' time perspective through the evaluation of personal events that they expect to occur in several successive years. Evaluation can be done regarding the vividness and richness of reported events (cf. Brandtstädter \& Wentura, 1994).

Moreover, since temporal perspective usually is conceived as a trait factor and, hence, might be rather unaffected by environmental stimulations, it should be examined whether temporal perspective causes an individual's proneness to devaluate future rewards. Causal interpretations of significant relationships between trait factors and behavioral measures should be treated with caution. However, dividing individuals into groups of high and low scorers on a future time perspective scale and then providing each group with a delay-discounting task should reveal differences between both groups regarding the discount rate, which, in turn, may have been caused by differences in the trait factor.

\section{The Duration of the Decision Process}

This section will deal with the effects of limited time on the making of decisions.

\section{Review of the Literature}

Any decision needs time for the processing of relevant information. Some decisions are very fast and are supposed not to be based on extensive information processing (Russo \& Schoemaker, 1989). Processing more information and changing the processing style from intuitive processing to analytic and algorithmic processing will require more time for making a decision. The time someone invests while he or she is making a decision is certainly dependent on a number of features of the situation surrounding the decision - for example, on the nature and complexity of the problem, on the subjective risk involved, on personal habits and experiences, and the like (McGrath \& Tschan, 2004).

Decision making under limited time resources. The amount of information processed before a decision is made certainly influences the time taken before a decision is reached. However, there is a norm for making decisions as soon as they can be made (McGrath \& Tschan, 2004). Thus, decision makers often adopt strategies to abbreviate information processing and the decision-making process. One well-known strategy is labeled the satisficing heuristic (Simon, 1955). That is, people search only until they find a solution that meets their minimal requirements and then adopt that solution without further search. Another strategy for abbreviating the decision process is to consider and eliminate alternatives in a sequential order (Russo \& Dosher, 1983). In this strategy, one compares each alternative with the previously considered one, and once an alternative has been eliminated, it is not reconsidered again. All of these heuristics certainly shorten the time until a decision is reached.

In many real-life situations (e.g., traffic control, emergency situations), shortage of time, or the existence of an external deadline, is a natural characteristic of the decision environment. This deadline, which limits or reduces the time available to make an optimal decision, shall define the term time pressure, and its effects on decision making will be reported within the following paragraphs. High levels of time pressure can lead to perceptual narrowing and, thus, to a reduced utilization of available cues, decreased vigilance, and reduction in working memory capacity (Klein, 1997; Orasanu, 1997; Orasanu \& Fischer, 1997; Stokes, Barnett, \& Wickens, 1987). In high-tempo event-driven environments, operators may have neither the time nor the attentional resources that are required to examine and evaluate multiple possible hypotheses (Maule, 1997; Orasanu \& Fischer, 1997; Wickens \& Flach, 1988). Staw, Sandelands, and Dutton (1981) posited that decision makers under time pressure have a tendency to show more rigid behavior, described as the failure to alter and adapt behavior to a new situation. This rigidity is a consequence of two effects of time pressure. First, information processing is altered. Less information is processed because there is a narrowing of the field of attention, and there is a simplification in information processing. Second, there is a constriction in the control system. For individuals, this manifests itself as a tendency toward dominant, welllearned, and habituated behavior, regardless of the needs of the specific situation. Both of these effects together may lead to a fixation of behavior (see also Betsch, Fiedler, \& Brinkmann, 1998). However, individuals who succeed in choosing a simplifying strategy that is well adapted for a given task perform better (Payne, Bettman, \& Johnson, 1993).

Time pressure might keep decision makers from choosing the best alternative since, it has been assumed, they divide their attention between estimating the elapsed time and selecting an alternative (Zakay, 1993; Zakay \& 
Wooler, 1984). Moreover, choice probabilities can change if time limits are imposed (e.g., Busemeyer, 1985; Busemeyer \& Townsend, 1993). For instance, Goldstein and Busemeyer (1992) studied performance in a task in which the participants had to choose between a small but certain loss and an unpredictable gamble that was equally likely to produce a loss or a win. When decision time was limited to $1 \mathrm{sec}$, the gamble was chosen more often than the certain loss. However, at longer decision times (up to $3 \mathrm{sec}$ ), preferences were reversed, so that the certain loss became the more frequent choice.

However, a decision that takes longer is not necessarily better. Eisenhardt (1989) found that decisions of top management teams made more quickly were of higher quality than decisions that took a longer time. In her study, fast decisions of management teams took between 1.5 and 4 months, whereas longer decisions took between 12 and 18 months. The fast decisions reflected more frequent meetings within the company, more real-time information being available, more experienced advisors, and a more integrative way of dealing with disagreements and conflicts. The fast decisions apparently did not suffer from the processes found in experimental research. On the contrary, fast decisions were made on the basis of more information; several alternatives were elaborated simultaneously, and these decisions were more successful.

Time pressure may enhance effort and lead to faster processing of information (Kerstholt, 1994; Maule, Hockey, \& Bdzola, 2000; Payne et al., 1993). Although many studies have shown that faster processing of information do sometimes correspond to less careful consideration of alternatives (Benson \& Beach, 1996), time pressure could, on the other hand, encourage the application of simplified and even more effective strategies (Staw et al., 1981). Payne et al. found that under moderate time pressure, people accelerated their processing and tried to work faster, but without changing their pattern of processing. As time pressure increased, shifts in the pattern of processing were observed; for example, subjects switched from alternative-based processing, in which they compared two alternatives and discarded the losing one, to attributebased processing, in which they discarded any alternative that did not fulfill the most important attribute. Because attribute-based decision making looks at all alternatives, but not at all dimensions of each alternative, it is generally less time consuming.

Time pressure may not have uniform effects on all types of decisions and under all circumstances. Kelly and Karau (1999) showed that initial preferences and task characteristics, as well as expertise, may mediate its effects. Time pressure affects novice and expert decision makers differently. The latter take time into account more explicitly than novices do. Expert decision makers more often ask explicitly about how much time they have left before they must commit to a decision. Moreover, they estimate the available time more precisely (Cohen, Freeman, \& Wolf, 1996).

Choice reaction time tasks. It has been shown that when the decision horizon is infinite (i.e., there is no deadline), the optimal strategy for decision making is to accumulate sensory evidence for one alternative over the other until a fixed threshold is reached. It appears that humans (and animals) accumulate information and make perceptual decisions in a manner close to this optimal strategy (Bogacz, Brown, Moehlis, Holmes, \& Cohen, 2006; Luce, 1986; Ratcliff \& Rouder, 1998). However, in most forced choice experiments, as well as in many situations in a natural environment, decisions must be made before a certain deadline has approached. Rapidly responding within a decision task might require a trade-off between the time needed for the decision maker to make a choice and the correctness of the choice. Several theoretical attempts deal with the nature of such speed-accuracy relations. One of the simplest conceptions of speed-accuracy relations has been presented by Yellot (1971). This model states that the decrement in accuracy produced by emphasizing speed is due to a failure of stimulus processing on some proportion of trials. These responses are called fast-guess responses, since they are initiated without any stimulus processing. These responses are much faster than usual responses, but they will have only a chance probability of being correct.

There exist numerous sequential-sampling models as alternatives to simple fast guessing (see, e.g., Dror, Busemeyer, \& Basola, 1999; Link, 1992; Nosofsky \& Palmeri, 1997; Ratcliff \& Smith, 2004). Although some authors have proposed a deterministic accumulation process (e.g., Brown \& Heathcote, 2005) in which the integration of information occurs in a ballistic manner, most models are based on the premise that the mental representation of stimuli is inherently noisy, and to make a decision about a stimulus, one must accumulate successive samples of this noisy stimulus representation until a certain criterion is obtained. The criterion determines which of two responses is made, and the time needed to attain the criterion determines the response time. The amount of information required for a response can be controlled by the subject, who can adjust the decision criterion. Trade-offs between speed and accuracy are made within these models with respect to the amount of evidence needed for a response, and changes of the values of the decision criteria alter the trade-off either to faster responses or to more accurate responses (Diederich, 2003). Time pressure will lower the decision criteria, which in turn will lead to shorter response times and higher error rates (e.g., Laver, 2000; Pachella \& Pew, 1968; Ruthruff, 1996).

Response time in choice tasks could be governed by an internal pacemaker, as Laming (1979) suggested. He claimed that people engage in premature stimulus sampling and that the onset of stimulus sampling occurs after a certain time interval has passed after a warning signal (or preceding reactions) in choice reaction time tasks. Dehaene (1993) proposed that perceptual information is transmitted by packets at regular moments in time. For each packet, a decision is made, either to respond immediately or to wait for the next packet in order to transmit more complete information to the response system. Several other studies have confirmed the hypothesis that internal timing is used to aid the speed of decision making (e.g., Grosjean, Rosenbaum, \& Elsinger, 2001; Lupker, Brown, $\&$ Colombo, 1997; Snodgrass, 1969). For example, Burle 
and Bonnet (2000) let their subjects work on a short-term memory-scanning task. They could show that varying the speed of a hypothetical internal clock by means of auditory clicks altered the time to respond as to whether a justpresented stimulus belonged to the set of stimuli previously memorized. They concluded that the probability that a response will be given is not regular in time and that there are some particular moments after stimulus presentation at which the response to this stimulation is more likely to occur (Burle, Macar, \& Bonnet, 2003). Other authors also have suggested that decision time is determined not only by the way information is accumulated and a decision is reached, but also by timing mechanisms (MacDonald \& Meck, 2004). People decide more quickly when the decision task has a predictable, temporally regular structure. This improvement in performance is typically attributed to the preparation of the motor system (Grosjean et al., 2001; Müller-Gethmann, Ulrich, \& Rinkenauer, 2003), but temporal preparation may also be mediated by sensorimotor association (Janssen \& Shadlen, 2005) or sensory processes (Ghose \& Maunsell, 2002). An example of a temporally structured decision task was used by Praamstra et al. (2006). In that study, subjects had to indicate as quickly as possible whether subsequently presented arrows pointed to the left or to the right. The stimulus onset asynchrony (SOA) between two stimuli was held constant but was changed for the last stimulus, which was presented either earlier or later than the preceding SOAs. It could be shown that reaction times were longer when the final SOA deviated from the preceding ones. Moreover, this behavioral finding was supported by the development of a slow preparatory brain potential between successive stimuli, the (contingent negative variation) $\mathrm{CNV}$. The $\mathrm{CNV}$ develops when people are engaged in time estimation (Macar \& Vidal, 2003, 2004; Pfeuty, Ragot, \& Pouthas, 2003; Pouthas, Garnero, Ferrandez, \& Renault, 2000), and its latency and amplitude correlate with the duration to be judged. In the Praamstra et al. study, the CNV reached its peak amplitude around the time of the expected stimulus onset.

\section{Summary, Conclusion, and Suggestions for Future Research}

The duration of the decision process is a variable magnitude, certainly depending on characteristics of the consequences that will follow, but also due to limited time resources (deadlines) and internal processes that initiate the selection for an option. The effect of time pressure on decision making is ambivalent, leading to both negative and positive consequences, depending on how many cognitive resources are still available for making "good" decisions. The instant at which a decision is finally made is determined by both the amount of information gathered during the decision-making process and an internal timing mechanism that triggers the response.

Beneficial effects of time pressure on decision making were usually explained either by the application of simplified strategies or by faster stimulus processing. However, a possible unifying framework that might account for the compensating that occurs with time pressure is time management. Time management means setting and pri- oritizing goals, scheduling tasks, and monitoring progress under limited time resources (e.g., Francis-Smythe, 2006), and its effectiveness depends partially on how precisely people are able to predict and judge the durations of tasks to be done (Francis-Smythe \& Robertson, 1999).

Even with decision making in choice reaction time tasks, it seems worthwhile to further examine how the timing of information processing is related to the time and outputs of decision making. Neuropsychological analyses might help in finding neuronal correlates and antecedents of the interconnections of both processes, which could be incorporated into current models of fast decision making.

\section{CONCLUSION}

Decision making and time are closely related, as can be seen by the five time-related topics that were identified and selected for this article. These were (1) the time that an option takes, (2) the time intervals that individuals may discriminate by means of a hypothesized decision rule, (3) the time between having made a decision and experiencing the consequences of that decision, (4) the temporal perspective of decision makers, and (5) the time that the decision process requires in order to be executed. Concerning each topic, seminal and recent literature was reviewed, and at the end of each section, the main results were summarized and suggestions for further research were made.

As this review suggests, time or duration plays a twofold role in decision making. On the one hand, physical (objective) time matters and has been related to decision making often and extensively, particularly in the domain of intertemporal choices. On the other hand, psychological (subjective) time has been shown to affect decisions. However, psychological time has received less attention in studies of decision making. One aim of this review was, therefore, to sensitize scientists to this lack of knowledge and to stimulate research on this issue.

\section{AUTHOR NOTE}

This article was written as part of the "European Platform for Life Sciences, Mind Sciences, and the Humanities" initiative of the Volkswagen Foundation. Correspondence concerning this article should be addressed to F. Klapproth, Institute of Psychology and Working Science, Berlin Institute of Technology, Franklinstrasse 28/29, 10587 Berlin, Germany (e-mail: klapproth@gp.tu-berlin.de).

\section{REFERENCES}

Ainslie, G. (1992). Picoeconomics: The strategic interaction of successive motivational states within the person. Cambridge: Cambridge University Press.

Allan, L. G. (1998). The influence of the scalar timing model on human timing research. Behavioural Processes, 44, 101-117.

Ariely, D., \& Loewenstein, G. (2000). The importance of duration in judgment and decision making. Journal of Experimental Psychology: General, 129, 508-523.

ARIELY, D., \& ZAKAY, D. (2001). A timely account of the role of duration in decision making. Acta Psychologica, 108, 187-207.

Barkley, R. A., Edwards, G., Laneri, M., Fletcher, K., \& Metevia, L. (2001). Executive functioning, temporal discounting, and sense of time in adolescents with attention deficit hyperactivity disorder (ADHD) and oppositional defiant disorder (ODD). Journal of Abnormal Child Psychology, 29, 541-556.

Bechara, A., Dolan, S., \& Hindes, A. (2002). Decision-making and 
addiction (part II): Myopia for the future of hypersensitivity to reward? Neuropsychologia, 40, 1690-1705.

Benson, L., \& BEACH, L. R. (1996). The effects of time constraints on the prechoice screening of decision options. Organizational Behavior \& Human Decision Processes, 67, 222-228.

Berlin, H. A., Rolls, E. T., \& KischKa, U. (2004). Impulsivity, time perception, emotion and reinforcement sensitivity in patients with orbitofrontal cortex lesions. Brain, 127, 1108-1126.

Berns, G. S., Laibson, D., \& Loewenstein, G. (2007). Intertemporal choice-toward an integrative framework. Trends in Cognitive Sciences, 11, 482-488.

Betsch, T., Fiedler, K., \& Brinkmann, J. (1998). Behavioral routines in decision making: The effects of novelty in task presentation and time pressure on routine maintenance and deviation. European Journal of Social Psychology, 28, 861-878.

BLock, R. A. (2003). Psychological timing without a timer: The roles of attention and memory. In H. Helfrich (Ed.), Time and mind II: Information processing perspectives (pp. 41-59). Göttingen: Hogrefe \& Huber.

Block, R. A., \& ZaKay, D. (1997). Prospective and retrospective duration judgments: A meta-analytic review. Psychonomic Bulletin \& Review, 4, 184-197.

Bogacz, R., Brown, E., Moehlis, J., Holmes, P., \& Cohen, J. D. (2006). The physics of optimal decision making: A formal analysis of models of performance in two-alternative force choice tasks. Psychological Review, 113, 700-765.

BRANDTStÄDTER, J., \& Wentura, D. (1994). Veränderungen der Zeitund Zukunftsperspektive im Übergang zum höheren Erwachsenenalter: Entwicklungspsychologische und differentielle Aspekte. Zeitschrift für Entwicklungspsychologie \& Pädagogische Psychologie, 26, 2-21.

BROWN, S. W. (1997). Attentional resources in timing: Interference effects in concurrent temporal and nontemporal working memory tasks. Perception \& Psychophysics, 59, 1118-1140.

Brown, S. [W.], \& Heathcote, A. (2005). A ballistic model of choice response time. Psychological Review, 112, 117-128.

Burle, B., \& Bonnet, M. (2000). High-speed memory scanning: A behavioral argument for a serial oscillatory model. Cognitive Brain Research, 9, 327-337.

Burle, B., Macar, F., \& Bonnet, M. (2003). Behavioral and electrophysiological oscillations in information processing: A tentative synthesis. In H. Helfrich (Ed.), Time and mind II: Information processing perspectives (pp. 209-232). Göttingen: Hogrefe \& Huber.

Busemeyer, J. R. (1985). Decision making under uncertainty: A comparison of simple scalability, fixed-sample, and sequential-sampling models. Journal of Experimental Psychology: Learning, Memory, \& Cognition, 11, 538-564.

Busemeyer, J. R., \& Townsend, J. T. (1993). Decision field theory: A dynamic-cognitive approach to decision making in an uncertain environment. Psychological Review, 100, 432-459.

Church, R. M., \& DeLuty, M. Z. (1977). Bisection of temporal intervals. Journal of Experimental Psychology: Animal Behavior Processes, 3, 216-228.

Church, R. M., \& GibBon, J. (1982). Temporal generalization. Journal of Experimental Psychology: Animal Behavior Processes, 8, 165-186.

Cohen, M. S., Freeman, J. T., \& Wolf, S. (1996). Meta-recognition in time-stressed decision making: Recognizing, critiquing, and correcting. Journal of the Human Factors \& Ergonomics Society, 38, 206-219.

Dehaene, S. (1993). Temporal oscillations in human perception. Psychological Science, 4, 264-270.

Dellaert, B. G. C., \& Kahn, B. E. (1999). How tolerable is delay? Consumers' evaluations of Internet Web sites after waiting. Journal of Interactive Marketing, 13, 41-54.

DiEDERICH, A. (2003). MDFT account of decision making under time pressure. Psychonomic Bulletin \& Review, 10, 157-166.

Dror, I. E., Busemeyer, J. R., \& Basola, B. (1999). Decision making under time pressure: An independent test of sequential sampling models. Memory \& Cognition, 27, 713-725.

EISENHARDT, K. M. (1989). Making fast strategic decisions in high-velocity environments. Academy of Management Journal, 32, 543-576.

Eisler, D. A., Eisler, H., \& Montgomery, H. (2004). A quantitative model for retrospective subjective duration. Neuroquantology, 4, 263291.
Fellows, L. K., \& FARAH, M. J. (2005). Dissociable elements of human foresight: A role for the ventromedial frontal lobes in framing the future, but not in discounting future rewards. Neuropsychologia, 43, 1214-1221.

Ferrara, A., Lejeune, H., \& Wearden, J. H. (1997). Changing sensitivity to duration in human scalar timing: An experiment, a review, and some possible explanations. Quarterly Journal of Experimental Psychology, 50B, 217-237.

Fillmore, M. T., \& Rush, C. R. (2002). Impaired inhibitory control of behavior in chronic cocaine users. Drug \& Alcohol Dependence, 66, 265-273.

ForZANO, L. B., \& Logue, A. W. (1992). Predictors of adult humans' selfcontrol and impulsiveness for food reinforcers. Appetite, 19, 33-47.

Francis-Smythe, J. A. (2006). Time management. In J. Glicksohn \& M. S. Myslobodsky (Eds.), Timing the future. The case for a timebased prospective memory (pp. 143-170). Hackensack, NJ: World Scientific.

Francis-Smythe, J. A., \& Robertson, I. T. (1999). On the relationship between time management and time estimation. British Journal of Psychology, 90, 333-347.

Frederick, S., Loewenstein, G., \& O'Donoghue, T. (2002). Time discounting and time preference: A critical review. Journal of Economic Literature, 40, 351-401.

Fredrickson, B. L., \& Kahneman, D. (1993). Duration neglect in retrospective evaluations of affective episodes. Journal of Personality \& Social Psychology, 65, 44-55.

FRIEDMAN, W. (1990). About time: Inventing the fourth dimension. Cambridge, MA: MIT Press.

Ghose, G. M., \& Maunsell, J. H. (2002). Attentional modulation in visual cortex depends on task timing. Nature, 419, 616-620.

Gibbon, J., Church, R. M., \& Meck, W. H. (1984). Scalar timing in memory. In J. Gibbon \& L. Allan (Eds.), Timing and time perception (Annals of the New York Academy of Sciences, Vol. 423, pp. 52-77). New York: New York Academy of Sciences.

Gilovich, T., Kerr, M., \& Medvec, V. H. (1993). Effect of temporal perspective on subjective confidence. Journal of Personality \& Social Psychology, 64, 552-560.

Glimcher, P. W., Kable, J., \& Louie, K. (2007). Neuroeconomic studies of impulsivity: Now or just as soon as possible? American Economic Review, 97, 142-147.

Goldstein, W. M., \& Busemeyer, J. R. (1992). The effect of "irrelevant" variables on decision making: Criterion shifts in preferential choice? Organizational Behavior \& Human Decision Processes, 52, 425-454.

Green, L., Fristoe, N., \& Myerson, J. (1994). Temporal discounting and preference reversals in choice between delayed outcomes. Psychonomic Bulletin \& Review, 1, 383-389.

Green, L., \& Myerson, J. (1996). Exponential versus hyperbolic discounting of delayed outcomes: Risk and waiting time. American Zoologist, 36, 496-505.

Green, L., Myerson, J., \& Macaux, E. W. (2005). Temporal discounting when the choice is between two delayed rewards. Journal of Experimental Psychology: Learning, Memory, \& Cognition, 31, 1121-1133.

Greene, A. L. (1986). Future-time perspective in adolescence: The present of things future revisited. Journal of Youth \& Adolescence, 15, 99-113.

Grosjean, M., Rosenbaum, D. A., \& Elsinger, C. (2001). Timing and reaction time. Journal of Experimental Psychology: General, 130, 256-272.

Hands, D. S., \& Avons, S. E. (2001). Recency and duration neglect in subjective assessment of television picture quality. Applied Cognitive Psychology, 15, 639-657.

Henson, J. M., Carey, M. P., Carey, K. B., \& Maisto, S. A. (2006). Associations among health behaviors and time perspective in young adults: Model testing with boot-strapping replication. Journal of Behavioral Medicine, 29, 127-137.

Ho, M.-Y., Mobini, S., Chiang, T.-J., Bradshaw, C. M., \& Szabadi, E. (1999). Theory and method in the quantitative analysis of "impulsive choice" behavior: Implications for psychopharmacology. Psychopharmacology, 146, 362-372.

Hodgins, D. C., \& ENGEL, A. (2002). Future time perspective in pathological gamblers. Journal of Nervous \& Mental Disease, 190, 775-780. 
Hoffman, W. F., Moore, M., Templin, R., McFarland, B., HitzeMANN, R. J., \& Mitchell, S. H. (2006). Neuropsychological function and delay discounting in methamphetamine-dependent individuals. Psychopharmacology, 188, 162-170.

Hui, M. K., \& TsE, D. K. (1996). What to tell consumers in waits of different lengths: An integrative model of service evaluation. Journal of Marketing, 60, 81-90.

HuI, M. K., \& ZHOU, L. (1996). How does waiting duration information influence customers' reactions to waiting for services? Journal of Applied Social Psychology, 26, 1702-1717.

Janssen, P., \& Shadlen, M. N. (2005). A representation of the hazard rate of elapsed time in macaque area LIP. Nature Neuroscience, $\mathbf{8}$, 234-241.

Jones, B., \& Rachlin, H. (2006). Social discounting. Psychological Science, 17, 283-286.

Kahneman, D., Fredrickson, B. L., Schreiber, C. A., \& RedelMEIER, D. A. (1993). When more pain is preferred to less: Adding a better end. Psychological Science, 4, 401-405.

Kahneman, D., \& TVERSKy, A. (1979). Prospect theory: An analysis of decision under risk. Econometrica, 47, 263-291.

Kelly, J. R., \& Karau, S. J. (1999). Group decision making: The effects of initial preferences and time pressure. Personality \& Social Psychology Bulletin, 25, 1342-1354.

Keough, K. A., Zimbardo, P. G., \& Boyd, J. N. (1999). Who's smoking, drinking, and using drugs? Time perspective as a predictor of substance use. Basic \& Applied Social Psychology, 21, 149-164.

Kerstholt, J. (1994). The effect of time pressure on decision-making behavior in a dynamic task environment. Acta Psychologica, 86, 89-104.

Kirby, K. N., \& Herrnstein, R. J. (1995). Preference reversals due to myopic discounting of delayed reward. Psychological Science, 6 , 83-89.

Kirby, K. N., \& Petry, N. M. (2004). Heroin and cocaine abusers have higher discount rates for delayed rewards than alcoholics or non-drugusing controls. Addiction, 99, 461-471.

KLApProth, F. (2002). The effect of study-test modalities on the remembrance of subjective duration from long-term memory. Behavioural Processes, 59, 39-48.

Klapproth, F. (2003a). Das modale Zeitgedächtnis. Untersuchungen zur Abhängigkeit der Gedächtnisleistung für kurze Zeitintervalle von der Reizmodalität. Doctoral dissertation. Available at web1.bib .unihildesheim.de/edocs/2003/372146562/meta/.

KLAPPROTH, F. (2003b). Notable results regarding temporal memory and modality. In H. Helfrich (Ed.), Time and mind II: Information processing perspectives (pp. 79-96). Göttingen: Hogrefe \& Huber.

Klapproth, F. (2007). Time perception, estimation paradigm, and temporal relevance. Perceptual \& Motor Skills, 104, 749-757.

Klapproth, F., \& Müller, M. (2008). Temporal generalization under time pressure in humans. Quarterly Journal of Experimental Psychology, 61, 588-600.

KLEIN, G. (1997). The recognition-primed decision (RPD) model: Looking back, looking forward. In C. Zsambok \& G. Klein (Eds.), Naturalistic decision making (pp. 285-292). Mahwah, NJ: Erlbaum.

Krishnamurthy, P., \& Kumar, P. (2002). Self-other discrepancies in waiting time decisions. Organizational Behavior \& Human Decision Processes, 87, 207-226.

KüHBERGER, A. (1998). The influence of framing on risky decisions: A meta-analysis. Organizational Behavior \& Human Decision Processes, 57, 23-55.

LAming, D. (1979). Autocorrelation of choice-reaction times. Acta Psychologica, 43, 381-412.

LAVER, G. D. (2000). A speed-accuracy analysis of word recognition in young and older adults. Psychology \& Aging, 15, 705-709.

Leclerc, F., Schmitt, B. H., \& Dubé, L. (1995). Waiting time and decision making: Is time like money? Journal of Consumer Research, 22, 110-119.

LELAND, D. S., \& PAulus, M. P. (2005). Increased risk-taking decisionmaking but not altered response to punishment in stimulant-using young adults. Drug \& Alcohol Dependence, 78, 83-90.

LESSING, E. E. (1972). Extension of personal future time perspective, age, and life satisfaction of children and adolescents. Developmental Psychology, 6, 457-468.

Levin, I. P., Schneider, S. L., \& Gaeth, G. J. (1998). All frames are not created equal: A typology and critical analysis of framing effects. $\mathrm{Or}$ ganizational Behavior \& Human Decision Processes, 76, 149-188.

Liberman, N., Sagristano, M. D., \& Trope, Y. (2002). The effect of temporal distance on level of mental construal. Journal of Experimental Social Psychology, 38, 523-534.

Liberman, N., \& Trope, Y. (1998). The role of feasibility and desirability considerations in near and distant future decisions: A test of temporal construal theory. Journal of Personality \& Social Psychology, 75, 5-19.

Lilienfeld, S. O., Hess, T., \& Rowland, C. (1996). Psychopathic personality traits and temporal perspective: A test of the short time horizon hypothesis. Journal of Psychopathology \& Behavioral Assessment, 18, 285-314.

LINK, S. W. (1992). The wave theory of difference similarity. Hillsdale, NJ: Erlbaum.

Loewenstein, G. (1996). Out of control: Visceral influences on behavior. Organizational Behavior \& Human Decision Processes, 65, 272-292.

Loewenstein, G., Weber, E., Hsee, C., \& Welch, E. (2001). Risk as feelings. Psychological Bulletin, 127, 267-286.

LuCE, R. D. (1986). Response times: Their role in inferring elementary mental organization. Oxford: Oxford University Press.

Lupker, S. J., Brown, P., \& Colombo, L. (1997). Strategic control in a naming task: Changing routes or changing deadlines? Journal of Experimental Psychology: Learning, Memory, \& Cognition, 23, 570-590.

MacAR, F., \& Vidal, F. (2003). The CNV peak: An index of decision making and temporal memory. Psychophysiology, 40, 950-954.

MACAR, F., \& VIDAL, F. (2004). Event-related potentials as indices of time processing: A review. Journal of Psychophysiology, 18, 89-104.

MacDonald, C. J., \& MECK, W. H. (2004). Systems-level integration of interval timing and reaction time. Neuroscience \& Biobehavioral Reviews, 28, 747-769.

Maule, A. J. (1997). Strategies for adapting to time pressure. In R. Flin, E. Salas, M. Strub, \& L. Martin (Eds.), Decision-making under stress: Emerging themes and applications (pp. 271-279). Brookfield, VT: Ashgate.

Maule, A. J., Hockey, G. R. J., \& Bdzola, L. (2000). Effects of timepressure on decision-making under uncertainty: Changes in affective state and information processing strategy. Acta Psychologica, 104, 283-301.

McElroy, T., \& Mascari, D. (2007). When is it going to happen? How temporal distance influences processing for risky-choice framing tasks. Social Cognition, 25, 495-517.

McGrath, J. E., \& Tschan, F. (2004). Temporal matters in social psychology. Washington, DC: American Psychological Association.

Montague, P. R., \& Berns, G. S. (2002). Neural economics and the biological substrates of valuation. Neuron, 36, 265-284.

Müller-Gethmann, H., Ulrich, R., \& Rinkenauer, G. (2003). Locus of the effect of temporal preparation: Evidence from the lateralized readiness potential. Psychophysiology, 40, 597-611.

Munichor, N., ERev, I., \& Lotem, A. (2006). Risk attitude in small timesaving decisions. Journal of Experimental Psychology: Applied, 12, 129-141.

Myerson, J., \& Green, L. (1995). Discounting of delayed rewards: Models of individual choice. Journal of the Experimental Analysis of Behavior, 64, 263-276.

Nosofsky, R. M., \& PAlmeri, T. J. (1997). An exemplar based random walk model of speeded classification. Psychological Review, 104, 266-300.

Orasanu, J. (1997). Stress and naturalistic decision making: Strengthening the weak links. In R. Flin, E. Salas, M. Strub, \& L. Martin (Eds.), Decision-making under stress: Emerging themes and applications (pp. 43-66). Brookfield, VT: Ashgate.

Orasanu, J., \& Fischer, U. (1997). Finding decisions in natural environments: The view from the cockpit. In C. Zsambok \& G. Klein (Eds.), Naturalistic decision making (pp. 343-357). Mahwah, NJ: Erlbaum.

Osuna, E. E. (1985). The psychological cost of waiting. Journal of Mathematical Psychology, 29, 82-105.

Pachella, R. G., \& PEW, R. W. (1968). Speed-accuracy trade-off in reaction time: Effect of discrete criterion times. Journal of Experimental Psychology, 76, 19-24. 
Payne, J. W., Bettman, J. R., \& Johnson, E. J. (1993). The use of multiple strategies in judgment and choice. In N. J. Castellan (Ed.), Individual and group decision making (pp. 19-39). Hillsdale, NJ: Erlbaum.

Petry, N. M., Bickel, W. K., \& Arnett, M. (1998). Shortened time horizons and insensitivity to future consequences in heroin addicts. Addiction, 93, 729-738.

Pfeuty, M., Ragot, R., \& Pouthas, V. (2003). When time is up: CNV time course differentiates the roles in the hemispheres in the discrimination of short tome durations. Experimental Brain Research, 151, 372-379.

PöPPEL, E. (1998). Erlebte Zeit und die Zeit überhaupt: Ein Versuch der Integration. In J. Aschoff, J. Assmann, \& J.-P. Blaser (Eds.), Die Zeit: Dauer und Augenblick (4th ed., pp. 369-382). München: Piper.

Pouthas, V., Garnero, L., Ferrandez, A. M., \& Renault, B. (2000). ERPs and PET analysis of time perception: Spatial and temporal brain mapping during visual discrimination tasks. Human Brain Mapping, 10, 49-60

Praamstra, P., Kourtis, D., Kwok, H. F., \& Oostenveld, R. (2006). Neurophysiology of implicit timing in serial choice reaction-time performance. Journal of Neuroscience, 26, 5448-5455.

Predebon, J. (1995). Prospective and retrospective time estimates as a function of clock duration. Perceptual \& Motor Skills, 80, 941-942.

RACHLIN, H. (1995). The value of temporal patterns in behavior. Current Directions in Psychological Science, 4, 188-192.

RAtClifF, R., \& Rouder, J. N. (1998). Modeling response times for two-choice decisions. Psychological Science, 9, 347-356.

Ratcliff, R., \& Smith, P. L. (2004). A comparison of sequential sampling models for two-choice reaction time. Psychological Review, 111, 333-367.

Read, D., Frederick, S., Orsel, B., \& Rahman, J. (2005). Four score and seven years from now: The date/delay effect in temporal discounting. Management Science, 51, 1326-1335.

Read, D., \& Loewenstein, G. (1999). Enduring pain for money: Decisions based on the perception and memory of pain. Journal of Behavioral Decision Making, 12, 1-17.

Redelmeier, D. A., \& Kahneman, D. (1996). Patient's memories of painful medical treatments: Real-time and retrospective evaluations of two minimally invasive procedures. Pain, 66, 3-8.

ReED, S. K. (2004). Cognition: Theory and applications. Belmont, CA: Wadsworth/Thomson.

Rinot, M., \& ZAKAY, D. (1999). Attending to duration (Tech. Rep.). Tel Aviv: Tel Aviv University, Department of Psychology.

RoHDE, K. I. M. (2005). The hyperbolic factor: A measure of decreasing impatience (Research Memoranda 044). Maastricht: Maastricht Research School of Economics of Technology and Organization.

Roy, M. M., Christenfeld, N. J. S., \& McKenzie, C. R. M. (2005). Underestimating the duration of future events: Memory incorrectly used or memory bias? Psychological Bulletin, 131, 738-756.

Russo, J. E., \& Dosher, B. A. (1983). Strategies for multiattribute binary choice. Journal of Experimental Psychology: Learning, Memory, \& Cognition, 9, 676-696.

Russo, J. E., \& Schoemaker, J. H. (1989). Decision traps. New York: Simon \& Schuster.

Ruthruff, E. (1996). A test of the deadline model for speed-accuracy tradeoffs. Perception \& Psychophysics, 58, 56-64.

Sagristano, M. D., Trope, Y., \& Liberman, N. (2002). Time-dependent gambling: Odds now, money later. Journal of Experimental Psychology: General, 131, 364-376.

SAMUELSON, P. (1937). A note on measurement of utility. Review of Economic Studies, 4, 155-161.

SAnna, L. J., \& Chang, E. C. (EDS.) (2006). Judgments over time: The interplay of thoughts, feelings, and behaviors. Oxford: Oxford University Press.

Sanna, L. J., Parks, C. D., Chang, E. C., \& Carter, S. E. (2005). The hourglass is half full or half empty: Temporal framing and the group planning fallacy. Group Dynamics: Theory, Research, \& Practice, 9, 173-188.

Sayette, M. A., Loewenstein, G., Kirchner, T. R., \& Travis, T. (2005). Effects of smoking urge on temporal cognition. Psychology of Addictive Behavior, 19, 88-93.

Schreiber, C. A., \& Kahneman, D. (2000). Determinants of the re- membered utility of aversive sounds. Journal of Experimental Psychology: General, 129, 27-42.

Schweighofer, N., Shishida, K., Han, C. E., OKamoto, Y., TanaKa, S. C., Yamawaki, S., \& Doya, K. (2006). Humans can adopt optimal discounting strategy under real-time constraints. PLoS Computational Biology, 2, 1349-1356.

Simon, H. A. (1955). A behavioral model of rational choice. Quarterly Journal of Economics, 69, 99-118.

Simons, J., Vansteenkiste, M., Lens, W., \& Lacante, M. (2004). Placing motivation and future time perspective theory in a temporal perspective. Educational Psychology Review, 16, 121-139.

Smart, R. G. (1968). Future time perspectives in alcoholics and social drinkers. Journal of Abnormal Psychology, 73, 81-83.

SNODGRass, J. G. (1969). Foreperiod effects in simple reaction time: Anticipation or expectancy? Journal of Experimental Psychology Monographs, 79(3, Pt. 2), 1-19.

Staw, B. M., Sandelands, L. E., \& Dutton, J. E. (1981). Threatrigidity effects in organizational behavior: A multilevel analysis. $\mathrm{Ad}$ ministrative Science Quarterly, 26, 501-524.

Stern, E., \& Koerber, S. (2000). Mentale Modele von Zeit und Zukunft. In J. Möller, B. Strauß, \& S. M. Jürgensen (Eds.), Psychologie und Zukunft (pp. 15-29). Göttingen: Hogrefe.

Stokes, A. F., Barnett, B. J., \& Wickens, C. D. (1987). Modeling stress and bias in pilot decision-making. In Proceedings of the 20th Annual Conference of the Human Factors Association of Canada (pp. 45-48). Mississauga, ON: Human Factors Association of Canada.

Strathman, A., Gleicher, F., Boninger, D. S., \& Edwards, C. S. (1994). The consideration of future consequences: Weighing immediate and distant outcomes of behavior. Journal of Personality \& Social Psychology, 66, 742-752.

Szelag, E., Kowalska, J., RymarczyK, K., \& Pöppel, E. (2002). Duration processing in children as determined by time reproduction: Implications for a few seconds temporal window. Acta Psychologica, 110, $1-19$

Takahashi, T., Oono, H., \& Radford, M. H. B. (2008). Psychophysics of time perception and intertemporal choice models. Physica A, 387, 2066-2074.

Trope, Y., \& Liberman, N. (2003). Temporal construal. Psychological Review, 110, 403-421.

Varey, C. A., \& Kahneman, D. (1992). Experiences extended across time: Evaluation of moments and episodes. Journal of Behavioral Decision Making, 5, 169-185.

WALlaCE, H. (1956). Future time perspective in schizophrenia. Journal of Abnormal Social Psychology, 52, 240-245.

WEARDEN, J. H. (1992). Temporal generalization in humans. Journal of Experimental Psychology: Animal Behavior Processes, 18, 134-144.

WEARDEN, J. H. (2003). Applying the scalar timing model to human time psychology: Progress and challenges. In H. Helfrich (Ed.), Time and mind II: Information processing perspectives (pp. 21-39). Göttingen: Hogrefe \& Huber.

Wearden, J. H. (2004). Decision processes in models of timing. Acta Neurobiologiae Experimentalis, 64, 303-317.

Wearden, J. H., Denovan, L., Fakhri, M., \& Haworth, R. (1997). Scalar timing in temporal generalization in humans with longer stimulus durations. Journal of Experimental Psychology: Animal Behavior Processes, 23, 502-511.

WeArden, J. H., \& Grindrod, R. (2003). Manipulation decision processes in the human scalar timing system. Behavioural Processes, 61, 47-56.

WeARden, J. H., \& McShane, B. (1988). Interval production as an analogue of the peak procedure: Evidence for similarity of human and animal timing processes. Quarterly Journal of Experimental Psychology, 40B, 363-375.

WELCH, E. (1999). The heat of the moment. Unpublished doctoral dissertation, Carnegie Mellon University: Department of Social and Decision Sciences.

Wickens, C. D., \& FlaCh, J. M. (1988). Information processing. In E. Wiener \& D. Nagel (Eds.), Human factors in aviation (pp. 111155). London: Academic Press.

Wills, T. A., Sandy, J. M., \& Yaeger, A. M. (2001). Time perspective and early-onset substance use: A model based on stress-coping theory. Psychology of Addictive Behaviors, 15, 118-125. 
Wilson, J. Q., \& Herrnstein, R. J. (1985). Crime and human nature. New York: Simon \& Schuster.

Wittmann, M., Leland, D. S., Churan, J., \& Paulus, M. P. (2007). Impaired time perception and motor timing in stimulant-dependent subjects. Drug \& Alcohol Dependence, 90, 183-192.

Wittmann, M., Leland, D. S., \& Paulus, M. P. (2007). Time and decision making: Differential contribution of the posterior insular cortex and the striatum during a delay discounting task. Experimental Brain Research, 179, 643-653.

YeLLOT, J. I. (1971). Corrections for fast guessing and speed-accuracytradeoff in choice reaction time. Journal of Mathematical Psychology, 8, 159-199.

ZAKAY, D. (1993). The impact of time perception processes on decision making under time stress. In O. Svenson \& A. J. Maule (Eds.), Time pressure and stress in human judgment and decision making (pp. 5972). New York: Plenum.

ZAKaY, D., \& WoOLER, S. (1984). Time pressure, training and decision effectiveness. Ergonomics, 27, 273-284.

ZALESKI, Z. (1996). Future anxiety: Concept measurement and preliminary research. Personality \& Individual Differences, 21, 165-174.

Zimbardo, P. G., \& BoYD, J. N. (1999). Putting time in perspective: A valid, reliable individual-differences metric. Journal of Personality \& Social Psychology, 77, 1271-1288.

Zimbardo, P. G., Keough, K. A., \& Boyd, J. N. (1997). Present time perspective as a predictor of risky driving. Personality \& Individual Differences, 23, 1007-1023.

\section{NOTES}

1. Block (2003) used the term experienced duration only for prospective time judgments - that is, judgments occurring after the subjects had been told to be aware of the duration of the stimuli. However, I prefer using this term for both prospective and retrospective temporal judgments, since both involve the real experience of time, as compared with imagined duration, which does not require the real experience of duration.

2. Similar figures, derived from a delay-discounting task and illustrating reward choices as a function of the delay of the small reward, plotted against the delay of the large reward, were presented in Ho, Mobini, Chiang, Bradshaw, and Szabadi (1999) and in Schweighofer et al. (2006).

3. In its original version (Church \& Gibbon, 1982), abs $\left(s^{*}-t\right)$ was divided by $s$. However, applying temporal generalization to humans revealed that changing $s$ to $t$ as the denominator fitted the empirical data of humans better.

4. The presentation of alternatives as either positive or negative will substantially influence a decision maker's choice (Kahneman \& Tversky, 1979; for reviews, see also Kühberger, 1998; Levin, Schneider, \& Gaeth, 1998). This effect, which is based solely on the presentational frame, is called the framing effect.

(Manuscript received March 1, 2008; revision accepted for publication July 16, 2008.) 